\title{
An original method of simulating the articular cartilage in the context of in vitro biomechanical studies investigating the proximal femur
}

\author{
TEODOR STEFAN GHEORGHEVICI ${ }^{1}$, EUGEN CARATA ${ }^{2}$, PAUL-DAN SIRBU $^{3}$, OVIDIU ALEXA $^{1,3}$, \\ MANUELA-GABI POROH ${ }^{3}$, ALEXANDRU FILIP ${ }^{3}$, NORIN FORNA ${ }^{3}$ and BOGDAN PUHA ${ }^{1,3}$ \\ ${ }^{1}$ Department of Orthopedics and Traumatology, 'Sf. Spiridon' County Clinical Emergency Hospital, 700111 Iasi; \\ ${ }^{2}$ Department of Machine-Tools and Equipment of The Faculty of Machine Constructions and Industrial Management, \\ 'Gheorghe Asachi' Technical University, 700050 Iasi; ${ }^{3}$ Department of Orthopedics and Traumatology, \\ Faculty of Medicine, 'Grigore T. Popa' University of Medicine and Pharmacy, 700115 Iasi, Romania
}

Received September 17, 2021; Accepted October 21, 2021

DOI: $10.3892 /$ etm.2022.11125

\begin{abstract}
Biomechanical testing is a necessity given the development of novel implants used in the osteosynthesis of hip fractures. The purpose of biomechanical testing is to recreate realistic conditions similar to the in vivo conditions. Although biomechanical testing of hip arthroplasty has been standardized since the 1970s, there is no consensus at present on testing methodology for osteosynthesis of hip fractures. Most biomechanical studies examining the fractures of the proximal femur in order to optimize implants opt for loading the bone-implant ensemble directly on the femoral head or using a metallic loading part. This loading technique fails to perform a mechanical stress distribution similar to in vivo conditions, which could alter the outcome. The present study aimed to design loading/unloading cups with mechanical properties that resemble those of the cartilage at the hip level. Through the impression and scanning of the cast models obtained, a digital 3D model was created in STL format and this was processed in order to obtain the computer numerical control (CNC) trajectories of the printing head. For prototyping using additive manufacturing technology, a thermoplastic polymer with biochemical properties, such as tensile strength, that resemble those of the adult hip and a Stratasys FORTUS $250 \mathrm{mc}$ CNC machine were used. Loading/unloading cups with similar anatomy and biomechanical forces compared with those of the adult hip were created, which allowed the experimental simulation of the conditions during walking.
\end{abstract}

Correspondence to: Professor Paul-Dan Sirbu or Dr Norin Forna, Department of Orthopedics and Traumatology, Faculty of Medicine, 'Grigore T. Popa' University of Medicine and Pharmacy, Str. Universității 16, 700115 Iasi, Romania

E-mail: pdsirbu@yahoo.com

E-mail: norin.forna@gmail.com

Key words: additive manufacturing technology, biomechanical tests, cartilage, hip, 3D printing

\section{Introduction}

Despite the development of novel implants based on biomechanical principles, the mechanical complications of osteosynthesis exhibit high rates of $1-32 \%$ (1-8). In order to optimize the surgical treatment and the implant used, biomechanical testing remains the gold standard. There is a multitude of biomechanical studies on the osteosynthesis of proximal femoral fractures, performed on both cadaveric and composite bone, in different loading modes, with heterogeneous results $(1-7,9,10)$. Although cadaveric bone has long been considered a 'gold standard' for biomechanical testing $(3,11)$, composite bone is an increasingly used alternative (9).

Knowing the area of contact of the hip joint and the distribution of pressure during daily activities is important in predicting the mechanism of mechanical complications after osteosynthesis, providing biomechanical reasons for preoperative planning and postoperative rehabilitation (12). While walking, the pressure on the femoral head is not constant or evenly distributed. Yoshida et al (12) stated that during walking, the peak pressure is located on the side roof of the acetabulum. During standing and sitting and while bending the knees, the peak pressures are located at the edge of the posterior horn (12). When climbing the stairs, the maximum pressure is found on the side roof, and this is higher than that when going down the stairs (12). Most studies $(2-6,9,10)$ perform the loading directly on the femoral head or through a metal piece that concentrates the force on a limited area of the head, thus not respecting the hip joint contact area $(2,9,10)$. The present study was performed to generate loading/unloading cups similar to the human acetabulum with similar biomechanical properties compared with the hip cartilage using additive technology in order to simulate the in vivo conditions while walking.

\section{Materials and methods}

Materials. After a comparative analysis of the materials compatible with the Stratasys FORTUS $250 \mathrm{mc}$ machine, 
Table I. Characteristics of the ABS and ASA material vs. hip cartilage $(1,2)$.

\begin{tabular}{lcccr}
\hline & \multicolumn{3}{c}{ Material } \\
\cline { 2 - 5 } Characteristics & ABS-P400 & ASA & ABS-M30 & Hip cartilage \\
\hline Tensile strength, $\mathrm{MPa}$ & 22 & 32.8 & 36 & 80 \\
Tensile modulus, $\mathrm{MPa}$ & 1,627 & $1,450-2,800$ & 2,400 & 2,210 \\
\hline
\end{tabular}

ABS-M30, acrylonitrile butadiene styrene M30, ABS-P400, acrylonitrile butadiene styrene P400, ASA, acrylonitrile styrene acrylate.

acrylonitrile butadiene styrene M30 (ABS-M30), a synthetic material with similar mechanical properties compared with the cartilage at the level of the adult hip (Table I), was selected (13). The characteristics of the ABS-M30 material were taken from the datasheet published by Stratasys, Ltd. The characteristics of the hip cartilage were taken from data reported in the literature (1). Acrylonitrile butadiene styrene (ABS) is a thermoplastic polymer of fossil source obtained through the polymerization of styrene and butadiene in the presence of acrylonitrile, which allows the manufacturing of models using additive manufacturing technology $(14,15)$.

To simulate the articular cartilage at the level of the femoral head and condyles and to achieve a uniform distribution of the compression forces, the loading was carried out using two 3D-printed parts made on a Stratasys FORTUS $250 \mathrm{mc}$ computer numerical control (CNC) machine (Stratasys, Ltd.) using ABS-M30 (Stratasys, Ltd.).

Methods. For biomechanical testing, forces between 208 and $1,400 \mathrm{~N}$ with frequencies between 0.2 and $1 \mathrm{~Hz}$ were used to simulate the normal gait of a $70 \mathrm{~kg}$ adult in vivo. The contact surface of the femoral head with the loading cup was $27.7 \mathrm{~cm}^{2}$. At maximum load $(1,400 \mathrm{~N})$, the force to be supported was $51.85 \mathrm{~N} / \mathrm{cm}^{2}$, which was lower than the tension modulus of the ABS-M30 material $\left(2.4 \times 10^{5} \mathrm{~N} / \mathrm{cm}^{2}\right)$, allowing its elastic deformation.

The loading/unloading cups were made through the impression of a Sawbones ${ }^{\circledR}$ (Pacific Research Laboratories, Inc.) femur model in casting gypsum (Figs. 1 and 2), which had been vacuum mixed for degasification. After the impression was performed and the casts were dried, the casts were painted for scanning using 3D Scan Spray (Helling GmbH).

These casts were then scanned using a 3D scanner, Creaform HandySCAN3D 300 (Ametek, Inc.) (Fig. 3), with a volumetric accuracy of $0.02 \mathrm{~mm}$, obtaining 3D digital models in STL format using the Creaform VXelements 1 software (https://www. creaform3d.com/en/metrology-solutions/3d-applications-software-platforms/vxmodel-scan-cad-software-module; Fig. 4).

3D digital models in STL format were processed using Insight software (v15.9; Stratasys, Ltd.; Figs. 4 and 5).

\section{Results}

Figs. 6-8 show models obtained after processing, with the CNC trajectories of the 3D printing head, in a thermally controlled atmosphere. The distance between the printed layers was $0.127 \mathrm{~mm}$.

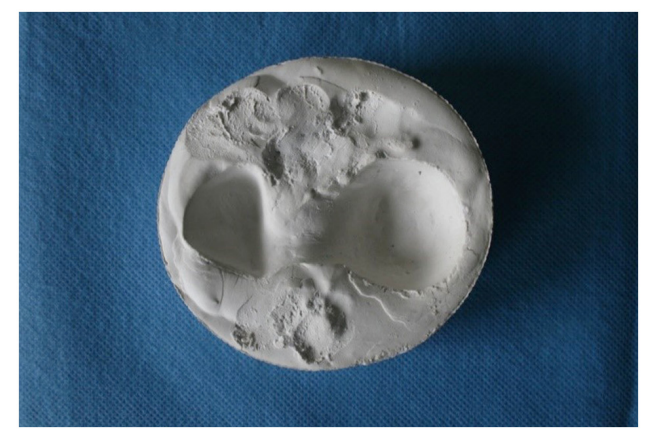

Figure 1. Gypsum cast for the proximal femur.

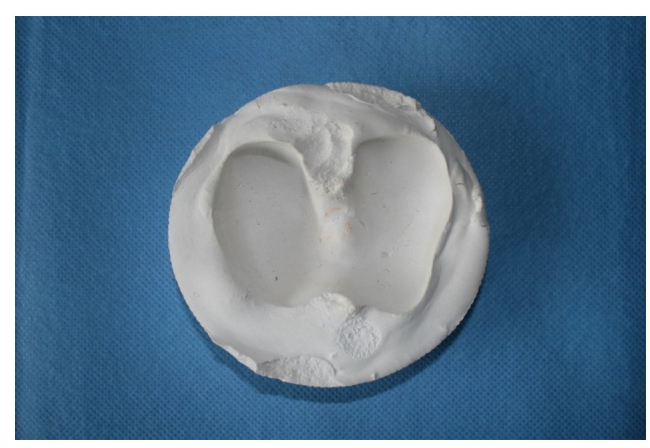

Figure 2. Gypsum cast for the distal femur.
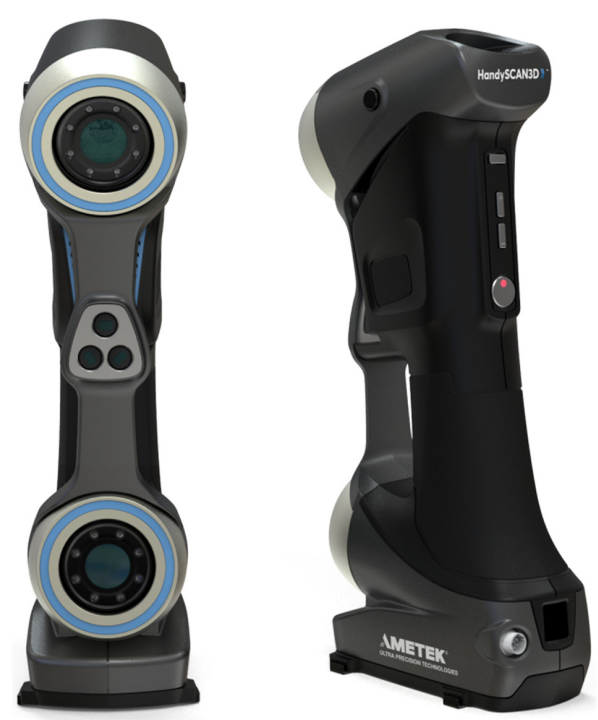

Figure 3. Creaform HandySCAN 3D laser scanner. 

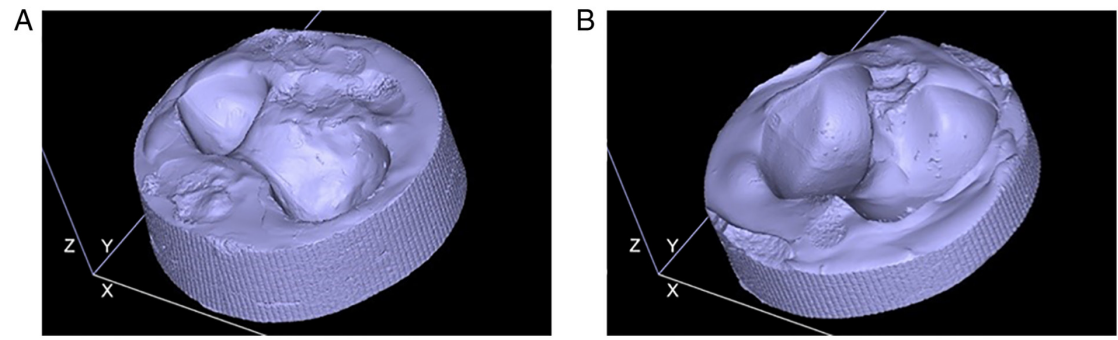

Figure 4. Digital model of (A) the femoral head and (B) condyles in STL format.
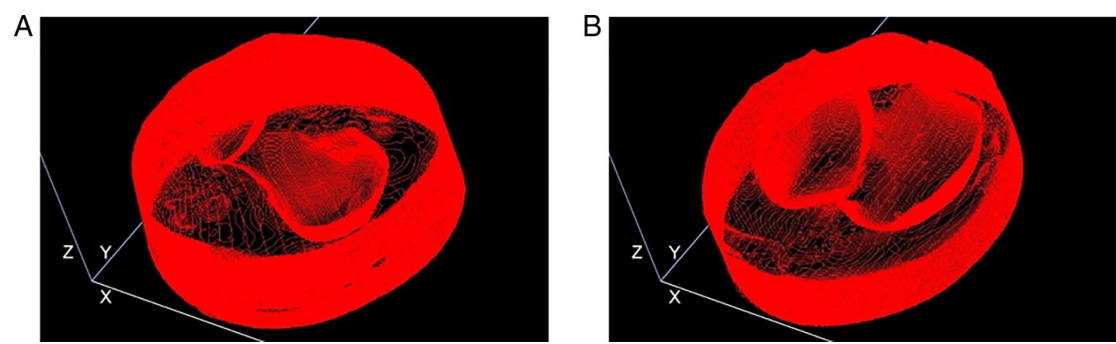

Figure 5. 3D model of (A) the femoral head and (B) condyles ready for 3D printing.

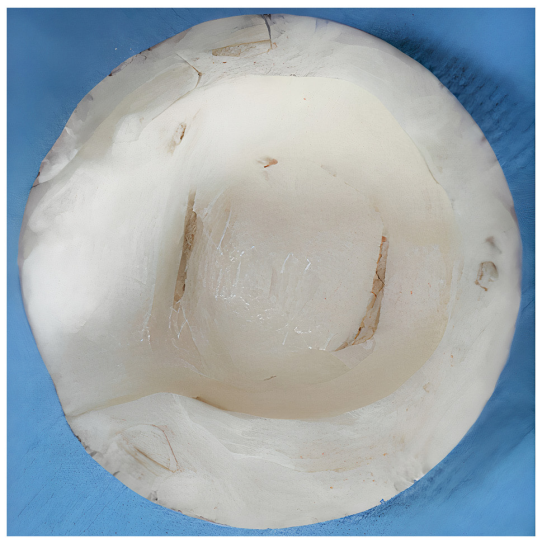

Figure 6. Femoral head support part. View from above.

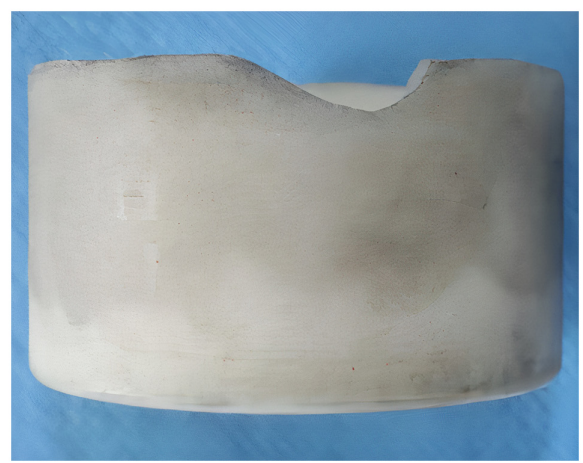

Figure 7. Femoral head support part. Lateral view.

The loading/unloading cups designed in this manner simulated the acetabular cavity and the tibial plateaus anatomically and could represent a good technical solution in order to optimize the distribution of the loading/unloading forces in the context of biomechanical experiments

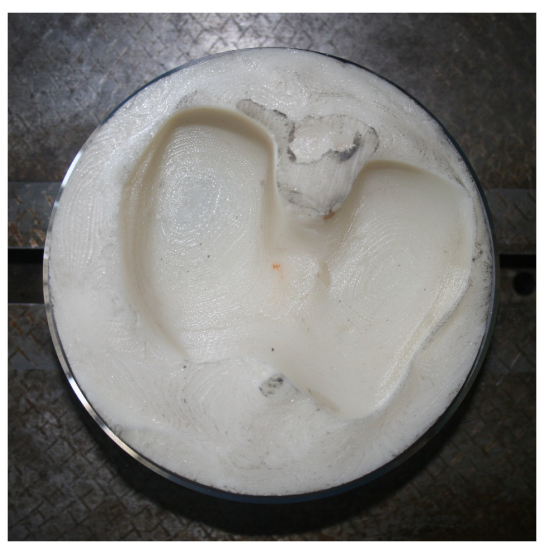

Figure 8. Femoral condyles support part. View from above.

\section{Discussion}

Most studies have attempted the loading directly on the femoral head, thus failing to respect the in vivo model $(2,9,10)$. Therefore, these studies $(2-6,9,10)$ have opted for loading the femoral head using a metallic plate that shows limited contact with the femoral head. Other authors have used a cadaveric hemipelvis, which was prepared to be tested (7). In a biomechanical study on a cadaveric femur (1), the femoral head was loaded using a methyl polymethacrylate cup. Unlike the aforementioned studies $(2-6,9,10)$, which attempted to load the femoral head by means of a rigid part with limited contact, Kane et al (8) understood the necessity of a uniform distribution of the mechanical stress at the level of the femoral head and used a urethane polymer (Smooth-Cast1 Urethane Series 300; Smooth-On, Inc.) to manufacture the loading cup. Although it ensures a uniform distribution of mechanical tension in the femoral head, the urethane polymer has properties similar to those of natural rubber 
and fails to transmit forces naturally (https://us.misumi-ec. com/maker/misumi/mech/product/ur/detail/detail.html).

The ABS material was used by Reddy et al (16) to design models of human bones using additive manufacturing technology. They used CT to scan various models of dry human bones and converted the resulting files into the STL format, which was used to reconstruct the digital model required for the 3D printing (16). Unlike Reddy et al (16), the present study used laser scanning to create the 3D model, which is a faster and less costly method.

It is well-known that, at the level of the femoral head, the articular cartilage exhibits a phenomenon of progressive degeneration following the loss of elasticity of the collagen fiber network (17). Research conducted by Kempson (17) and confirmed by Silver et al (18) has demonstrated that, at the level of the femoral head, the superficial layer of the cartilage exhibits a decrease in pressure resistance from $150 \mathrm{MPa}$ at the age of 7 years to $80 \mathrm{MPa}$ at the age of 90 years and from $60 \mathrm{MPa}$ at the age of 7 years to $10 \mathrm{MPa}$ at the age of 85 years. In a subsequent study, Silver et al (13) identified an elastic module of the articular cartilage at the level of the femoral head with values of 7.0 GPa at parallel stress and 2.21 GPa at perpendicular stress. In the present study, the ABS-M30 material used to design the loading cup exhibited an elasticity module of $2.4 \mathrm{GPa}$, which resembles the mechanical properties of adult hip cartilage.

$3 \mathrm{D}$ printing is currently widely used in orthopedic practice, particularly for pre-surgery planning in arthroplasties and traumatology. Tack et al (14), in a systematic literature review published in 2016, which analyzed the utility of 3D printing in medical practice, identified 227 articles whose authors used additive manufacturing technology in the current practice. Tack et al (14) identified the advantages of this technique: reduction of surgical time, improvement of outcome and decrease of intra-surgery irradiation time. In the field of research of orthopedics, notable progress has been made regarding the mathematic modelling of the haversian structure of the bone in view of designing experimental models using additive manufacturing technology (15). Nevertheless, the authors of the present study admit that there are important limitations related to the printing material. Biomechanical studies simulating human cartilage using additive manufacturing technology were not identified in the literature. The selected material exhibits similar tensile strength and tensile modulus compared with the cartilage at the level of the adult human hip, thus mimicking the mechanical properties of adult hip cartilage.

In conclusion, manufacturing the loading cups from the ABS-M30 material using the method proposed in the present study allowed the realistic reproduction of the anatomy and the distribution of the forces at the level of the hip in in vitro biomechanical studies simulating walking.

\section{Acknowledgements}

Not applicable.

\section{Funding}

No funding was received.

\section{Availability of data and materials}

All data generated or analyzed during this study are included in this published article.

\section{Authors' contributions}

EC and TSG conceived the study. EC, TSG, PDS and BP developed the methodology. OA, AF and PDS performed formal analysis. AF, NF and MGP performed data curation. TSG and NF wrote the initial draft of the manuscript. EC and PDS confirm the authenticity of all the raw data. OA, BP EC and PDS revised the manuscript in light of the literature findings. All authors provided resources. All authors have read and approved the final manuscript.

\section{Ethics approval and consent to participate}

Not applicable.

\section{Patient consent for publication}

Not applicable.

\section{Competing interests}

The authors declare that they have no competing interests.

\section{References}

1. Wang J, Ma JX, Jia HB, Chen Y, Yang Y and Ma XL: Biomechanical evaluation of four methods for internal fixation of comminuted subtrochanteric fractures. Medicine (Baltimore) 95: e3382, 2016.

2. Schaefer TK, Spross C, Stoffel KK and Yates PJ: Biomechanical properties of a posterior fully threaded positioning screw for cannulated screw fixation of displaced neck of femur fractures. Injury 46: 2130-2133, 2015.

3. Röderer G, Moll S, Gebhard F, Claes L and Krischak G: Side plate fixation vs. intramedullary nailing in an unstable medial femoral neck fracture model: A comparative biomechanical study. Clin Biomech (Bristol, Avon) 26: 141-146, 2011.

4. Windolf M, Braunstein V, Dutoit C and Schwieger K: Is a helical shaped implant a superior alternative to the Dynamic Hip Screw for unstable femoral neck fractures? A biomechanical investigation. Clin Biomech (Bristol, Avon) 24: 59-64, 2009.

5. Strauss E, Frank J, Lee J, Kummer FJ and Tejwani N: Helical blade versus sliding hip screw for treatment of unstable intertrochanteric hip fractures: A biomechanical evaluation. Injury 37: 984-989, 2006.

6. Rosenblum SF, Zuckerman JD, Kummer FJ and Tam BS: A biomechanical evaluation of the Gamma nail. J Bone Joint Surg Br 74: 352-357, 1992.

7. Santoni BG, Nayak AN, Cooper SA, Smithson IR, Cox JL, Marberry ST and Sanders RW: Comparison of femoral head rotation and varus collapse between a single lag screw and integrated dual screw intertrochanteric hip fracture fixation device using a cadaveric hemi-pelvis biomechanical model. J Orthop Trauma 30: 164-169, 2016.

8. Kane P, Vopat B, Heard W, Thakur N, Paller D, Koruprolu S and Born C: Is tip apex distance as important as we think? A biomechanical study examining optimal lag screw placement. Clin Orthop Relat Res 472: 2492-2498, 2014.

9. Basso T, Klaksvik J and Foss OA: Statistical consequences of using bone mineral density to pair cadaver femurs in comparative ex vivo hip fracture studies. Bone Joint Res 3: 317-320, 2014.

10. Basso T, Klaksvik J, Syversen U and Foss OA: A biomechanical comparison of composite femurs and cadaver femurs used in experiments on operated hip fractures. J Biomech 47: 3898-3902, 2014. 
11. Deneka DA, Simonian PT, Stankewich CJ, Eckert D, Chapman JR and Tencer AF: Biomechanical comparison of internal fixation techniques for the treatment of unstable basicervical femoral neck fractures. J Orthop Trauma 11: 337-343, 1997.

12. Yoshida H, Faust A, Wilckens J, Kitagawa M, Fetto J and Chao EY: Three-dimensional dynamic hip contact area and pressure distribution during activities of daily living. J Biomech 39: 1996-2004, 2006.

13. Silver FH, Bradica G and Tria A: Elastic energy storage in human articular cartilage: Estimation of the elastic modulus for type II collagen and changes associated with osteoarthritis. Matrix Biol 21: 129-137, 2002.

14. Tack P, Victor J, Gemmel P and Annemans L: 3D-printing techniques in a medical setting: A systematic literature review. Biomed Eng Online 15: 115, 2016

15. Robles-Linares JA, Ramírez-Cedillo E, Siller HR, Rodríguez CA and Martínez-López JI: Parametric modeling of biomimetic cortical bone microstructure for additive manufacturing. Materials (Basel) 12: 913, 2019.
16. Reddy MV, Eachempati K, Gurava Reddy AV and Mugalur A: Error analysis: How precise is fused deposition modeling in fabrication of bone models in comparison to the parent bones? Indian J Orthop 52: 196-201, 2018.

17. Kempson GE: Age-related changes in the tensile properties of human articular cartilage: A comparative study between the femoral head of the hip joint and the talus of the ankle joint. Biochim Biophys Acta 1075: 223-230, 1991.

18. Silver FH, Bradica G and Tria A: Relationship among biomechanical, biochemical, and cellular changes associated with osteoarthritis. Crit Rev Biomed Eng 29: 373-391, 2001.

This work is licensed under a Creative Commons Attribution-NonCommercial-NoDerivatives 4.0 International (CC BY-NC-ND 4.0) License. 